\title{
MOBILE SECURITY USING WI-FI SIGNAL STRENGTH
}

\author{
Aditya Kumar Dwivedi ${ }^{1}$, Girjesh Kumar Mishra ${ }^{2}$, Mohan Babu Bansal ${ }^{3}$ \\ ${ }^{1}$ School of Computer Science and Information Technology, DAVV University, Indore (M.P) \\ ${ }^{2}$ School of Computer Science and Information Technology, DAVV University, Indore (M.P) \\ ${ }^{3}$ School of Computer Science and Information Technology, DAVV University, Indore (M.P)
}

\begin{abstract}
Android is an open source full stack platform for developing applications for mobile phones. Android based smart phones as they are portable devices the vulnerability of theft exists. As for as security is concerned, cost is major issue where the cost of element is not so high, so a cost effective technique is needed to protect phones using existing resources.

Currently available method is using GPS, but GPS does not work well at indoor locations, so WI-FI signal strength can be used. It is easy to develop an application that can be applied for securing phones in a particular area as android is an open source platform. Here WI-FI router signal strength is used as a medium to track as well as to protect the devices. In this work an effective security application is presented for android based smart phones that use WI-FI signal strength as a parameter. The application is suitable for identifying position in indoor locations so that mobile phone can become the theft free.
\end{abstract}

Keywords: - Android, Wi-Fi, Security, Signal Strength, WPS

\section{INTRODUCTION}

Wi-Fi positioning system (WPS) is widely being studied in many fields. WPS usually uses Wi-Fi signals from already installed private and public Wi-Fi APs in order to provide the location based service (LBS). WPS complements the measurement error of global positioning system (GPS) in the center of the city or indoor [2].

A smart phone is also known as a cellular phone and a hand phone. Mobile phone is used to make and receive telephone calls over a wide area. Mobile phones also support a wide variety of other services such as text messaging, mms, email, internet access, infrared, Bluetooth, business application, gaming, photography, line chatting, conferencing etc. Mobile phones are playing important vital role and have become an integral part of our life. Mobile phones are being extensively used by every person in the institutes and colleges [3].

Mobile phones and the use of internet in mobiles led to revolution in the field of communication system and lifestyle of the people. People use mobile devices to find application related to their current location these days.

Due to the location-based system in mobiles it is easy to use the mobile phones anywhere or in any situation for gathering location related information. Indoor locationbased services are a general class of computer program-level services used to include specific controls for indoor locations. Indoor locations are used in a variety of contexts, such as finding malls, nearby indoor objects, entertainment places and work places.

In this paper, we propose a personal indoor/outdoor WPS system and security on the smart phone using RSS
(Received Signal Strength) of signals from dense Wi-Fi access points dedicated for localization [10].

\section{PROPOSED ALGORITHM}

RSS from each AP is measured three times and the mean value of three RSSs is calculated. Here root mean square (RMS) is used to find the threshold value (T). We use the difference between the mean value and each training value. If the difference is below a threshold $(\mathrm{T})$, the training value is withdrawn and then the mean of filtered training values is calculated again. Finally, the mean value is compared with the value of database and a proper location on the map is found. Then this location is saved in a database and again location is calculated, then compared to last location if both are same then device is there where it should otherwise it is moved.

\subsection{Area Used}

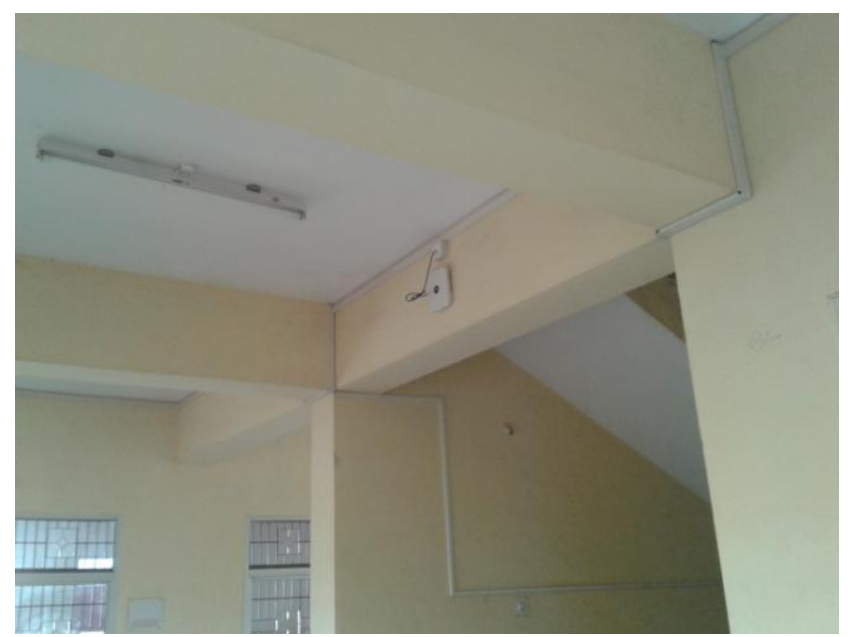

Fig: $1 \mathrm{Wi}-\mathrm{Fi}$ access point 


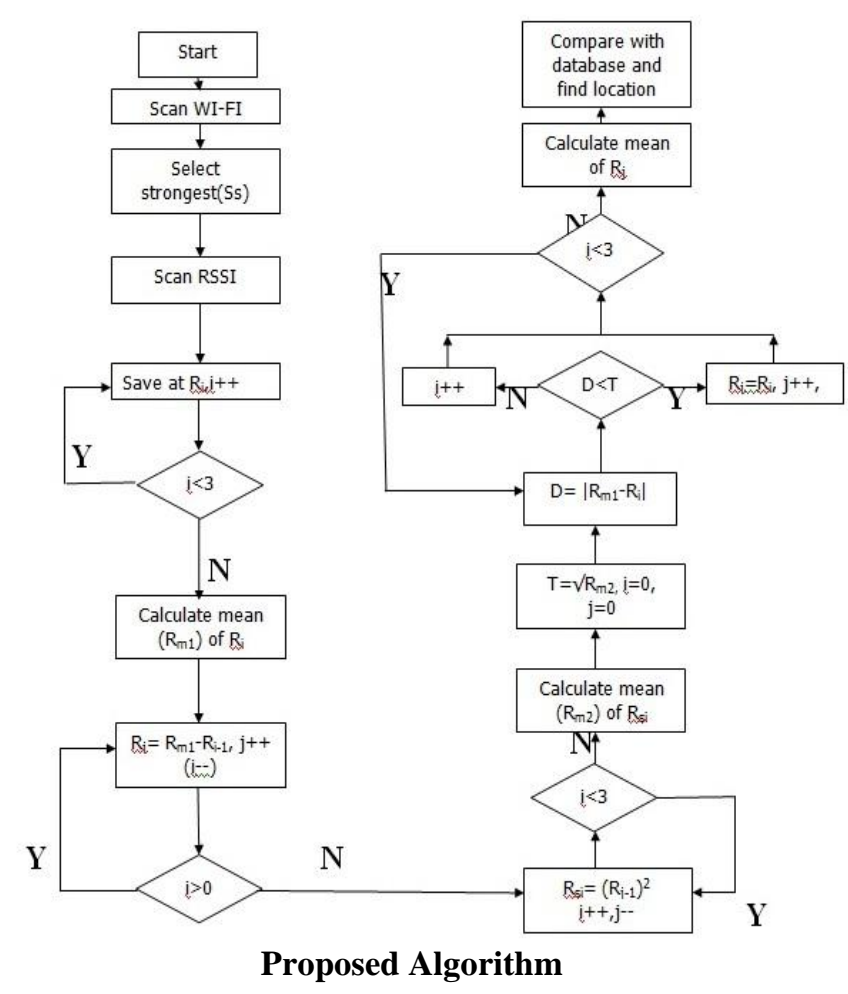

Ss : Strongest Signal Received

$\mathbf{i}, \mathbf{j}:$ No. of iteration

$\mathbf{R}$ : Training value of RSS

R'j : Mean Difference

D : Difference of Threshold

T : Threshold

Rsi :Square of mean Difference

\subsection{Algorithm Features}

\begin{tabular}{|l|l|}
\hline Parameter & Proposed Algorithm \\
\hline No. of WI-FI used & $<4$ \\
\hline Threshold Calculation & Practical \\
\hline Signal & Strong, Weak \\
\hline Indoor Location & Yes \\
\hline Security & Yes \\
\hline Algorithm & Standard Deviation \\
\hline $\begin{array}{l}\text { Working Methodology } \\
\text { for Strong and Weak } \\
\text { Signals }\end{array}$ & Different \\
\hline Dedicated WI-FI & Yes \\
\hline
\end{tabular}

\section{EXPERIMENTAL ENVIRONMENT}

The experiment was performed in a floor, which locates in SCSIT DAVV building, DAVV University. An area of $20 \mathrm{~m}$ by $25 \mathrm{~m}$ was used for the experiment. One Wi-Fi AP was installed for the experiment. The Smartphone is Galaxy-S Duos made by Samsung and has Android 4.0 O/S. Figure 1 shows the floor plan and AP mounted in the ceiling for the experiment. The threshold for the filtering calculated using the algorithm. If the last location (See Fig: 3) is different from the current location the message is sent to alternate phone no. specifying the new location

\section{DATABASE CONSTRUCT}

RSS is measured at each point on the floor and saved at the database (see Figure 2). The measured RSSs are stored at the database with the cell ID and SSID. And root mean square value

Table: 1

\begin{tabular}{|l|l|l|l|}
\hline S no & SSID & $\begin{array}{l}\text { Mean } \\
\text { Value }\end{array}$ & Location \\
\hline 1 & CiscoAp & 44 & MCA lab door \\
\hline 2 & CiscoAp & 39 & $\begin{array}{l}\text { Electronic lab } \\
\text { door }\end{array}$ \\
\hline$\ldots$ & $\ldots$ & $\ldots$ & $\ldots$ \\
\hline$\ldots$. & $\ldots$. & $\ldots$. & $\ldots$. \\
\hline.. $\mathrm{n}$ & CiscoAP & $\ldots$. & $\ldots$ \\
\hline
\end{tabular}

Table: 2

\begin{tabular}{|l|l|}
\hline Last Location & New Location \\
\hline MCA lab door & M Tech lab \\
\hline
\end{tabular}

\section{CONCLUSIONS}

We developed an indoor WPS and security for Android smart phones. Positioning using Wi-Fi signals is easy to implement and requires lower cost than other localization systems. We installed AP dedicated for localization at specific locations to improve positioning accuracy. We proposed a new algorithm to filter error signals and find the location of the smart phone and send sms if location is changed without permission. It acquires a proper scan time and threshold thereby yielding a low error rate. We expect the indoor WPS for smart phones to be used at various places and provide security.

\section{REFERENCES}

[1] Available at http://www.directionsmag.com/articles

[2] Satya Komatineni and Dave MacLean, "proandroid 4", XXX publication, YYY Edition, $20 Z Z$.

[3] Wallace Jackson, Android Apps for absolute beginners

[4] Available at http://www.intechopen.com/download/get/type/pdfs/i d/13525

[5] Available at http://www.directionsmag.com/articles/10-thingsyou-need-to-know-about-indoor-positioning/324602

[6] Available at http://www.psut.jo/sites/osama/4.pdf

[7] http://www.doi.ieeecomputersociety.org/10.1109/M DM.2012.68

[8] Availale at http://mobilware.org/2009/presentations/Mobilware2 009_Papliatseyeu_FM_Positioning.PDF

[9] Volume 2 Issue 3,2013 journaleacademiauitmt.uitm.edu.my/index.php?

[10] An Analysis of Wi-Fi Based Indoor Positioning Accuracy ortus. https://www.ortus.rtu.lv/science/en/publications/1237 2/fulltext 